\title{
Evaluation of insulin sensitivity by hyperinsulinemic-euglycemic clamps using stable isotope-labeled glucose
}

\author{
Yuanyuan Zhang ${ }^{1}$, Lina $\mathrm{Xu}^{2}$, Xiaohui Liu ${ }^{2}$ and Yiguo Wang ${ }^{1}$
}

\begin{abstract}
Dear Editor,
Insulin resistance is a critical factor in the pathogenesis of metabolic diseases such as obesity, nonalcoholic fatty liver disease (NAFLD) and type 2 diabetes (T2D) ${ }^{1}$. For many years, the hyperinsulinemic-euglycemic clamp has been used as a "gold standard" method to accurately measure insulin action in vivo ${ }^{2}$. It is widely used in humans, dogs, rats and mice. During the clamp, glucose kinetics, including the rates of endogenous glucose production and disposal in mice, are conventionally assessed with tracers ${ }^{3}$. The radioactive tracer $\left[3-{ }^{3} \mathrm{H}\right]$ glucose is commonly used because it is sensitive and massless, but it is harmful to our environment, and cannot be used in humans because it is hazardous if introduced into the body ${ }^{3}$. Therefore, medical research has turned to stable isotopes as alternative tracers. Although many studies have successfully established the clamp method using stable isotopes in humans, no method has been developed for laboratory mice because of the limitations of mass spectrometry, which requires the infusion of a large dose of stable isotope and a large volume of blood ${ }^{4-8}$.

In this study, we have successfully devised a sensitive method using $\left[6,6-{ }^{2} \mathrm{H}\right]$ glucose as a tracer in mice. $\left[6,6-{ }^{2} \mathrm{H}\right]$ glucose is a stable (non-radioactive) naturally occurring isotope with no known harmful effects and similar metabolic effects to normal glucose ${ }^{5}$. It can be distinguished from natural isotopomers of glucose (i.e., with other isotopic fine structures) using a high resolution mass spectrometer. To establish this method, we tested it
\end{abstract}

\footnotetext{
Correspondence: Xiaohui Liu (xiaohuiliu@biomed.tsinghua.edu.cn) or Yiguo Wang (wangyiguo@biomed.tsinghua.edu.cn) ${ }^{1}$ MOE Key Laboratory of Bioinformatics, Tsinghua-Peking Center for Life Sciences, School of Life Sciences, Tsinghua University, Beijing 100084, China ${ }^{2}$ National Protein Science Technology Center, Tsinghua University, Beijing 100084, China
}

in a high-fat diet (HFD)-induced obese mouse model, which is well known and widely used in metabolism research $^{9-12}$. Compared to mice fed with a regular diet (RD), HFD-induced obese mice had significantly higher body weight, plasma insulin levels, glucose production measured by pyruvate tolerance test (PTT), glucose intolerance evaluated by glucose tolerance test (GTT) and insulin insensitivity assessed by insulin tolerance test (ITT) (Fig. 1a-e). All the results indicate that glucose production and insulin resistance were dramatically increased in HFD-fed mice compared to RD-fed animals.

To evaluate insulin action and glucose metabolism in vivo, we performed hyperinsulinemic-euglycemic clamp studies using $\left[6,6{ }^{2} \mathrm{H}\right]$ glucose as a tracer (Fig. 1f, g). A bolus of $\left[6,6-{ }^{2} \mathrm{H}\right]$ glucose $\left(600 \mu \mathrm{g} \mathrm{kg}^{-1}\right)$ was administered via catheter followed by continuous infusion of $\left[6,6-{ }^{2} \mathrm{H}\right] \mathrm{glu}-$ cose at the rate of $30 \mu \mathrm{g} \mathrm{kg}^{-1} \mathrm{~min}^{-1}$ for 90 min to maintain steady-state conditions. During the clamp, we monitored the blood glucose levels, plasma insulin levels and glucose infusion rate (GIR) (Fig. 1h, i, Supplementary Figure S1a). At the steady state, GIR in HFD-fed mice is $12.17 \pm 1.09$ $\mathrm{mg} \mathrm{kg}{ }^{-1} \mathrm{~min}^{-1}$, which is much lower than that in RD-fed mice $\left(22.10 \pm 1.23 \mathrm{mg} \mathrm{kg}^{-1} \mathrm{~min}^{-1}\right)$, indicating that insulin sensitivity is decreased in HFD-fed mice (Fig. 1i).

In our experiments, levels of glucose and $\left[6,6-{ }^{2} \mathrm{H}\right]$ glucose were simultaneously measured using mass spectrometer. To distinguish $\left[6,6{ }^{2} \mathrm{H}\right]$ glucose from natural isotopomers of glucose $(M+2)$, we used a high resolution mass spectrometer (Orbitrap) coupled with an ultra-high performance liquid chromatography (UPLC) system. It was recently reported that the Orbitrap machine has a mass resolution of 100,000 , and can therefore resolve isotopic fine structures ${ }^{13}$. We performed this assay based on a mass resolution of 140,000 , which enables us to differentiate oxygen-18 $\left({ }^{18} \mathrm{O}\right),{ }^{13} \mathrm{C}$ and ${ }^{2} \mathrm{H}$ isotopes of 


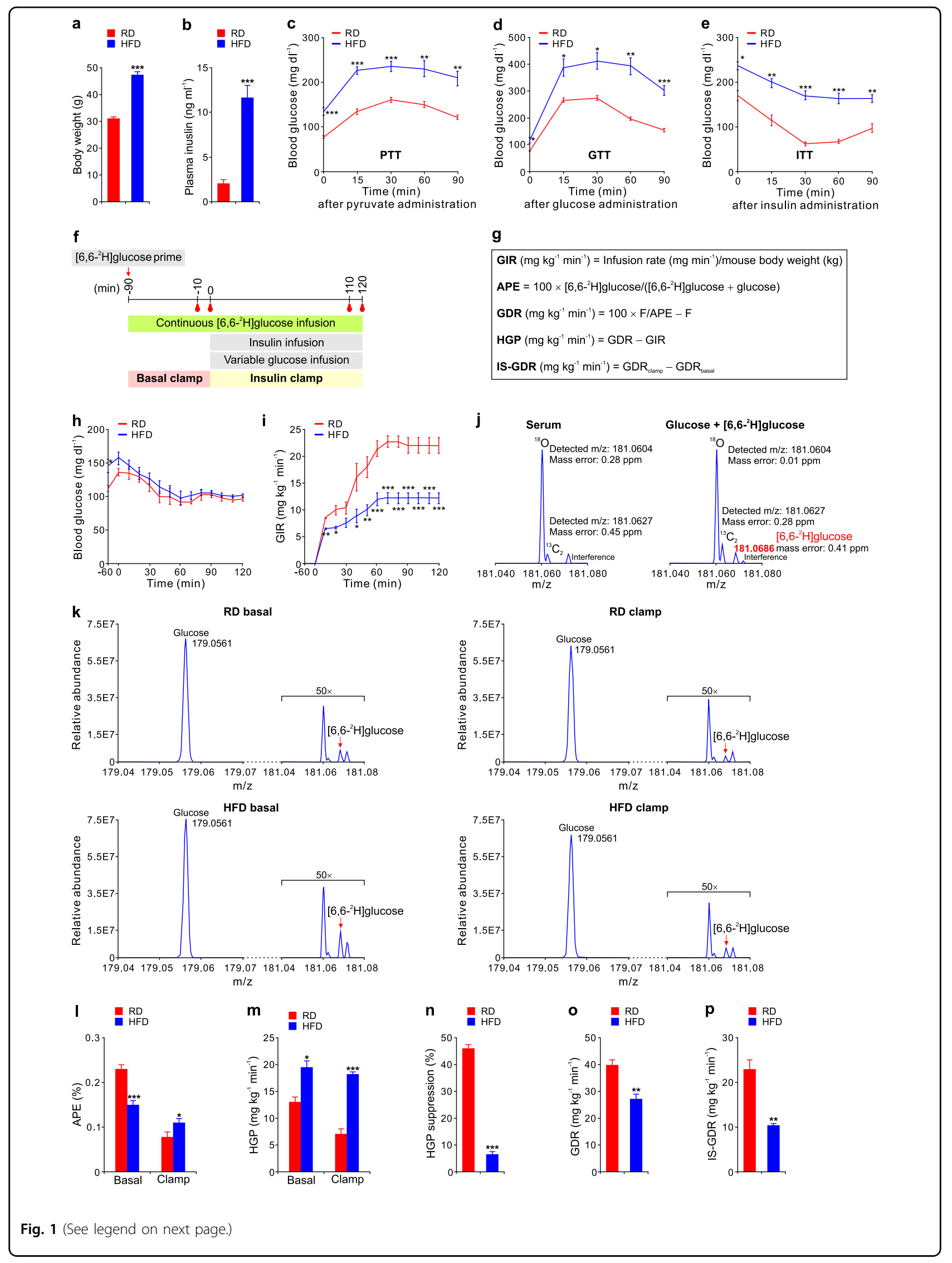


(see figure on previous page)

Fig. 1 Evaluation of insulin sensitivity by hyperinsulinemic-euglycemic clamps using $\left[6,6-{ }^{2} \mathbf{H}\right]$ glucose in mice. a-e Comparison of body weight (a), plasma insulin levels (b), pyruvate tolerance test (PTT, $\mathbf{c}$ ), glucose tolerance test (GTT, d) and insulin tolerance test (ITT, e) in mice fed with a regular diet (RD) and a high-fat diet (HFD) for 16 weeks. $\mathbf{f} A$ time-line of the procedure for performing the insulin clamp. Blood samples were taken at time $-10,0,110$, and $120 \mathrm{~min}$ for further analyses. $\mathbf{g}$ The equations used to calculate and evaluate insulin sensitivity. $\mathbf{f}$ indicates the constant isotope infusion rate. $\mathbf{h}$, i Blood glucose levels (h) and glucose infusion rate $(G I R, \mathbf{i})$ measured during clamp studies. $\mathbf{j}$ Representative MS spectra showing the isotopic fine structures of glucose $(\mathrm{M}+2)$ in mouse serum and in a standard mixture of glucose $\left(1 \mathrm{mg} \mathrm{ml}^{-1}\right)$ and $\left[6,6^{-}{ }^{2} \mathrm{H}\right] \mathrm{glucose}\left(1 \mu \mathrm{g} \mathrm{ml} \mathrm{l}^{-1}\right)$. $\mathbf{k}$ Representative MS spectra of monoisotopic peaks and M+2 isotopic fine structures of glucose with infused $\left[6,6-{ }^{2} H\right]$ glucose extracted from the serum of mice fed a RD or HFD for 16 weeks. The intensity of the M+2 isotopic envelopes is magnified by 50 -fold on each spectrum. All peaks are displayed using relative abundance on the same scale. I, $\mathbf{m}$ Atom percent excess (APE, I) and hepatic glucose production (HGP, $\mathbf{m}$ ) under basal and clamp conditions are shown. $\mathbf{n}-\mathbf{p}$ HGP suppression (n), glucose disposal rate (GDR, o), and insulin-stimulated GDR (IS-GDR, $\mathbf{p})$ are shown. Data are shown as mean \pm s.e.m. ${ }^{*} P<0.05,{ }^{* *} P<0.01,{ }^{* *} P<0.001, n=5$

glucose $(M+2)$, thereby improving the detection sensitivity of exogenous $\left[6,6-{ }^{2} \mathrm{H}\right]$ glucose. As shown in the left panel of Fig. $1 \mathrm{j}$, no natural ${ }_{2} \mathrm{H}_{2}$ isotope was detected in serum before $\left[6,6-{ }^{2} \mathrm{H}\right]$ glucose infusion. Natural ${ }^{18} \mathrm{O}$ and ${ }^{13} \mathrm{C}_{2}$ isotopic peaks were clearly resolved with mass errors of less than $1 \mathrm{ppm}$. However, when we analyzed a standard mixture solution containing $1 \mu \mathrm{g} \mathrm{ml}^{-1}\left[6,6-{ }^{2} \mathrm{H}\right] \mathrm{glu}-$ cose and $1 \mathrm{mg} \mathrm{ml}^{-1}$ glucose (1:1000), a signal from $\left[6,6-{ }^{2} \mathrm{H}\right]$ glucose with $0.41 \mathrm{ppm}$ mass error appeared which was separate from the ${ }^{18} \mathrm{O}$ and ${ }^{13} \mathrm{C}_{2}$ isotopic peaks (right panel of Fig. 1j).

Next, we measured the relative levels of $\left[6,6-{ }^{2} \mathrm{H}\right]$ glucose and glucose from mice fed with a RD or HFD (Fig. 1k). $\left[6,6-{ }^{2} \mathrm{H}\right]$ glucose and glucose were quantified respectively using the calibration curves in Supplementary Table S1. It turned out that the ratio of $\left[6,6-{ }^{2} \mathrm{H}\right]$ glucose and glucose can be represented using the ratio of the corresponding chromatographic areas. As expected, the $\left[6,6^{2}{ }^{2} \mathrm{H}\right]$ glucose levels were more dramatically decreased in mice during the insulin clamp than in the basal state (Fig. 1k). In addition, plasma enrichment, expressed as atom percent excess (APE), was much higher in the basal state and lower in the insulin clamp state in RD-fed mice than in HFD-fed mice (Fig. 11). In the basal state, there is lower hepatic glucose production in RD-fed mice than in HFD-fed mice, and this is much clearer during the insulin clamp, indicating a failure of insulin suppression on HGP in HFD-fed mice as a reflection of hepatic insulin resistance (Fig. $1 \mathrm{~m}, \mathrm{n}$ ). The decreased glucose disposal rate (GDR) in HFD-fed mice indicated systemic insulin resistance, while insulinstimulated GDR (IS-GDR) and insulin-induced suppression of plasma FFA levels reflected the relative insulin resistance in muscle and white adipose tissue (WAT) of HFD-fed mice, respectively (Fig. 1o, p, Supplementary Figure S1b). The reduced insulin sensitivity was further confirmed by immunoblots of pAKT in liver, skeletal muscle and WAT of mice fed a HFD (Supplementary Figure S1c). Altogether, these data clearly demonstrated that our method, using $\left[6,6-{ }^{2} \mathrm{H}\right]$ glucose as a tracer, successfully evaluates the impaired insulin action and glucose metabolism in diet-induced obese mice.

In summary, we have successfully developed a sensitive hyperinsulinemic-euglycemic clamp method using $\left[6,6-{ }^{2} \mathrm{H}\right]$ glucose as a tracer followed by identification with a high resolution mass spectrometer, which generates similar results to methods based on the radioactive tracer ${ }^{9}, 10,14$. The radioactive tracer is harmful to the environment, very expensive, and restricted by regulations. Previously reported methods in humans used a high dosage of $\left[6,6{ }^{2} \mathrm{H}\right]$ glucose infusion, which had a nonnegligible effect on glucose metabolism ${ }^{4-8}$. In contrast, we used a very low dose of $\left[6,6-{ }^{2} \mathrm{H}\right]$ glucose, which had no effect on blood glucose levels, and was distinguished from the natural isotopomers of glucose by high resolution mass spectrometry. Therefore, this method makes the low dosage infusion of stable isotope-labeled glucose in humans possible for further sensitive detection and is suitable for use in medical research. Our method can also be combined with serum metabolomics ${ }^{15}$ based on highthroughput analyses by mass spectrometry, which would allow the analysis of many metabolites in parallel.

Methods are available in Supplementary Information.

\section{Acknowledgements}

This work was supported by grants from the Ministry of Science and Technology of the People's Republic of China (2016YFC1304803 and 2017 YFA0503404 to Y.W.) and the National Natural Science Foundation of China (31625014, 31471127,31621063 and 31500956 to Y.W., 81501776 to X.L.).

\section{Author contributions}

Y.Z., L.X., X.L. and Y.W. designed the study and analyzed the data. Y.Z. performed mouse and clamp experiments; L.X. carried out mass spectrometry analysis. Y.Z., X.L. and Y.W. wrote the paper. All authors reviewed and commented on the manuscript.

\section{Competing interests}

The authors declare no competing interests.

\section{Publisher's note}

Springer Nature remains neutral with regard to jurisdictional claims in published maps and institutional affiliations. 
Supplementary Information accompanies the paper at (https://doi.org/ 10.1038/s41421-018-0016-3).

Received: 23 November 2017 Accepted: 24 January 2018

Published online: 17 April 2018

\section{References}

1. Samuel, V. T. \& Shulman, G. I. Mechanisms for insulin resistance: common threads and missing links. Cell 148, 852-871 (2012).

2. Ayala J. E., et al. Hyperinsulinemic-euglycemic clamps in conscious, unrestrained mice. J Vis Exp. 57, 3188 (2011).

3. Vella, A. \& Rizza, R. A. Application of isotopic techniques using constant specific activity or enrichment to the study of carbohydrate metabolism. Diabetes 58, 2168-2174 (2009).

4. Friedlander, A. L. et al. Training-induced alterations of carbohydrate metabolism in women: women respond differently from men. J. Appl. Physiol. 85, 1175-1186 (1998).

5. Gregg, C. T., Hutson, J. Y., Prine, J. R., Ott, D. G. \& Furchner, J. E. Substantial replacement of mammalian body carbon with carbon-13. Life. Sci. 13, 775-782 (1973).

6. Haigh, J. W. et al. Assessment of glucose turnover in normal man with the use of a non-radioactive isotopically labelled preparation, $[6,6-2 \mathrm{H}]$ glucose, as tracer. Clin. Sci. 63, 437-440 (1982).
7. Lee, G. A. et al. The acute effects of HIV protease inhibitors on insulin suppression of glucose production in healthy HIV-negative men. J. Acquir. Immune Defic. Syndr. 52, 246-248 (2009).

8. Reinauer, $\mathrm{H}$. et al. Determination of glucose turnover and glucose oxidation rates in man with stable isotope tracers. J. Clin. Chem. Clin. Biochem. 28, 505-511 (1990)

9. Han, J. et al. The CREB coactivator CRTC2 controls hepatic lipid metabolism by regulating SREBP1. Nature 524, 243-246 (2015).

10. Li, P. et al. Adipocyte NCoR knockout decreases PPARgamma phosphorylation and enhances PPARgamma activity and insulin sensitivity. Cell 147, 815-826 (2011).

11. Wang, Y., Vera, L., Fischer, W. H. \& Montminy, M. The CREB coactivator CRTC2 links hepatic ER stress and fasting gluconeogenesis. Nature 460, 534-537 (2009).

12. Lutz, T. A. \& Woods, S. C. Overview of animal models of obesity. Curr. Protoc Pharmacol. Chapter 5, Unit 5.61 (2012).

13. Kaufmann, A. Strategy for the elucidation of elemental compositions of trace analytes based on a mass resolution of 100,000 full width at half maximum Rapid. Commun. Mass. Spectrom. 24, 2035-2045 (2010).

14. Perry, R. J. et al. Hepatic acetyl CoA links adipose tissue inflammation to hepatic insulin resistance and type 2 diabetes. Cell 160, 745-758 (2015).

15. James, E. L. \& Parkinson, E. K. Serum metabolomics in animal models and human disease. Curr. Opin. Clin. Nutr. Metab. Care. 18, 478-483 (2015). 